\title{
Kajian Kriteria Perencanaan Dan Metode Pelaksanaan Struktur Reservoir
}

\author{
Johannes TARIGAN ${ }^{1} \cdot$ Simon Dertha TARIGAN $^{2}$. \\ Ernie Shinta Yosephine SITANGGANG ${ }^{3}$ Philip Amsal Aprianto GINTING ${ }^{4}$
}

\begin{abstract}
Reservoir is a building used as a place to hold clean water before being distributed. Artificial resevoir can be a steel tank or reinforced concrete tub. For reservoir that is planned to accommodate large amounts of water capacity, it is usually more effective to use reinforced concrete. Evaluation and analysis of reservoir construction is one of the important aspects to ensure that the reservoir design meets the requirements of strength and stability, as well as functional abilities. The problem that often occurs in reservoir buildings is the occurrence of uncontrolled uplift which results upward movement in the construction of the reservoir, and also the reservoir building often decreases differently due to improper foundation systems. This different decline resulted in cracks on the floor of the reservoir building which in turn will cause damage and malfunction of the reservoir construction. This paper contains a study of planning evaluation and analysis, and the method of implementation of several constructions of reservoir structures that have been carried out. The results of this study are expected to provide input and help planners and contractors to build reinforced concrete reservoirs that comply with the correct planning criteria, so that the building can function properly as planned.
\end{abstract}

Kata kunci: reservoir, uplift, gagal, safety, service ability

\section{Latar Belakang}

Struktur yang direncanakan untuk menampung air harus memiliki kekuatan, daya tahan dan bebas dari kemungkinan adanya retak. Struktur reservoir juga harus memiliki permeabilitas yang rendah untuk mencegah korosi. Tebal minimum dari struktur ditetapkan minimum 200 $\mathrm{mm}$. Tebal selimut beton ditetapkan $40 \mathrm{~mm}$. (Anchor, 1993)

Kondisi tanah turut mempengaruhi struktur terutama air permukaan untuk mencegah terangkatnya struktur akibat gaya air. Kondisi daya dukung tanah yang jelak juga kemungkinan dapat meningkatkan penurunan tanah, apalagi bila terjadi kemungkinan perbedaan penurunan tanah yang dapat menyebabkan keretakan pada struktur sehingga data penyelidikan tanah sangat diperlukan. Lantai reservoir dapat didesain sebagai pelat flat slab dengan dinding kantilever.

Material beton yang digunakan berdasarkan Design Considerations for Enviromental Engineering Concrete Structures (ACI 350.4R-04) dengan nilai slump 0,55 dengan mutu antar 35-40 MPa.

Bila reservoir dalam keadaan kosong, bila berat struktur lebih ringan dari berat air maka struktur bisa terangkat. Untuk mencegah hal ini, maka ditetapkan nilai faktor keamanan dari perbandingan berat struktur terhadap berat air harus sama dengan atau lebih dari 1,1-1,25.

\footnotetext{
${ }^{1}$ Staf Pengajar Teknik Sipil Universitas Sumatera Utara

${ }^{2}$ Staf Pengajar Teknik Sipil Universitas Katolik Santo Thomas email: simondertha2003@yahoo.com

${ }^{3}$ Staf Pengajar Program Studi Teknik Sipil Politeknik Negeri Medan

${ }^{4}$ Program Studi Teknik Sipil Universitas Sumatera Utara
} 
Berat struktur dapat diperbesar dengan menambah tebal pelat lantai atau menambah luas pelat lantai seperti terlihat pada gambar 1 berikut.
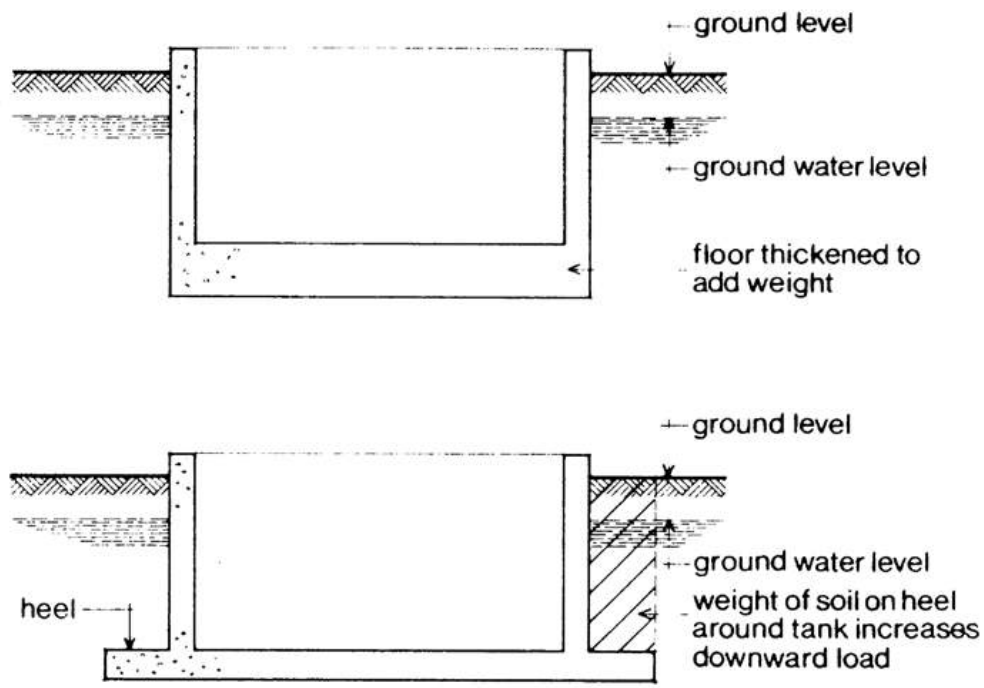

Gambar 1. Metode untuk Mencegah Uplift Struktur Reservoir (Anchor, 1993).

\section{Metodologi Studi}

Untuk metode perencanaan terhadap struktur yang diperbaiki dilakukan: setelah melihat gambar asbuilt drawing, foto-foto dokumentasi, dan lain-lain maka diusulkan tahapan penanganan bangunan tersebut sebagai berikut :

- Memeriksa langsung pelat beton dengan melakukan core drill dan melakukan penyelidikan tanah.

- Melakukan kajian teknis dengan program PLAXIS (mengapa bangunan tersebut turun).

- Solusi penanganan (apakah dipakai perkuatan pondasi atau tambahan pemberat agar tidak terjadi gaya uplift jika banjir) lengkap dengan spesifikasi dan RAB serta gambar kerja.

Untuk struktur dengan bangunan baru dilakukan:

- Melakukan survei topografi

- Melakukan penyelidikan tanah

- Desain struktur dengan memperhitungkan kapasitas reservoir dan data tanah yang sudah didapatkan. Berat struktur dibanding dengan berat air harus sama dengan atau lebih besar dari 1,1 sampai 1,25

\section{Hasil Penelitian dan Pembahasan}

Untuk kasus pertama, struktur reservoir mengalami penurunan serta kemiringan akibat berat sebelah, dimana pada bagian buffel bangunan terisi seluruhnya oleh batu kerikil, sedangkan di bagian lain kosong (gaya uplift sewaktu banjir lebih besar dari berat sendiri bangunan). Berikutnya dilakukan peninjauan lapangan, terjadi kemiringan pada struktur, sehingga dilakukan berbagai penelitian terhadap struktur, dari hasil Cone Penetration Test (CPT) diperoleh hasil perbedaan beda tinggi terhadap struktur. 

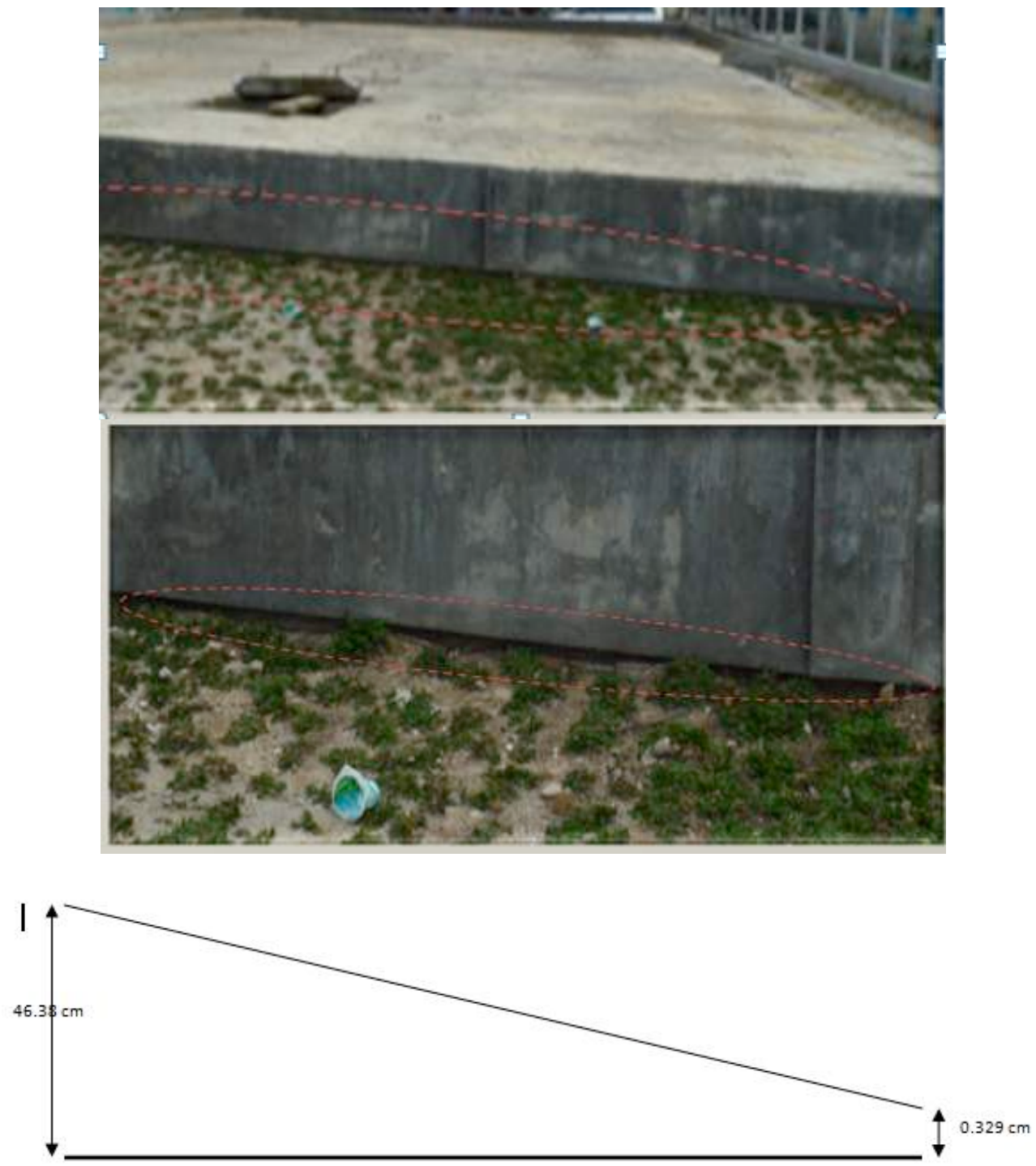

Gambar 2. Penurunan Beda Tinggi Kasus Pertama

Setelah melihat gambar asbuilt drawing, foto-foto dokumentasi, dan lain-lain maka diusulkan tahapan penanganan struktur untuk kasus pertama tersebut sebagai berikut :

- Memeriksa langsung pelat beton dengan melakukan core drill dua titik.

- Melakukan sondir ulang dua titik.

- Melakukan kajian teknis dengan program PLAXIS (mengapa bangunan tersebut turun).

- Solusi penanganan (apakah dipakai perkuatan pondasi atau tambahan pemberat agar tidak terjadi gaya uplift jika banjir) lengkap dengan spesifikasi dan RAB serta gambar kerja.

Untuk instalasi air minum kasus pertama diperoleh hasil pengamatan bahwa naiknya reservoir akibat gaya uplift pasti terjadi jika tidak dilakukan treatment. Uplift terjadi pada saat reservoir kosong dan muka air tanah $1 \mathrm{~m}$ di bawah permukaan tanah asli. Dalam kondisi ini safety factor hanya 0,1798. Seperti hasil observasi di lapangan terjadi kenaikan reservoir sampai $1,2 \mathrm{~m}$. Untuk mengatasi masalah naiknya reservoir tidak cukup hanya dengan menambah timbunan 2,0 $\mathrm{m}$ di atas pelat penutup lantai dan juga penebalan lantai reservoir 
sebesar $25 \mathrm{~cm}$. Jika hal ini dilakukan masih terjadi heaving (naiknya reservoir) sebesar 6,477 $\mathrm{cm}$. Untuk mengatasi masalah heaving yang terjadi akibat uplift maka dilakukan pemasangan ground anchored dengan jumlah dua per potongan dan jarak pemasangan $8 \mathrm{~m}$. Berdasarkan British Standard Code of Practice for Ground Anchorages (BS 8081:1989), penggunaan ground anchored maka tidak terjadi lagi kenaikan reservoir ketika reservoir kosong. Penebalan pelat lantai tetap harus dilakukan untuk mengatasi gaya uplift dan juga kemungkinan pelat lantai telah mengalami kerusakan selama ini. Perlu dilakukan penebalan lantai penutup reservoir karena adanya beban timbunan yang cukup besar. Perlu dievaluasi juga water proofing dengan kondisi kemungkinan telah terjadinya kerusakan struktur.

Pada kasus kedua dilakukan investigasi visual dan ditemukan hal-hal berikut:

a. Sistem pelat di bagian dasar bangunan yang merupakan sistem flat slab memiliki kecenderungan untuk mengalami kegagalan punching shear akibat gaya uplift yang bekerja ketika reservoir dalam keadaan kosong.

b. Kerusakan yang salah satunya berupa retak pada material beton menjadi perhatian khusus, mengingat kegunaan bangunan sebagai penampungan dan berada di bawah permukaan tanah dapat mengakibatkan tulangan baja mengalami korosi yang dapat mengurangi integritas bangunan. Elemen yang memiliki lebar retak melebihi batas ijin perlu diantisipasi dengan pelapisan dengan menggunakan material waterproof.

c. Sistem dinding perimeter perlu diperhitungkan kembali kekuatannya terhadap beban tambahan yang diakibatkan oleh terjadinya kenaikan muka air tanah. Kenaikan muka air tanah dapat meningkatkan gaya lateral yang terjadi pada dinding.

d. Beberapa perbaikan/perkuatan sudah direncanakan, seperti penambahan area kolom yang meningkatkan tahanan pelat terhadap kegagalan punching shear.

e. Beberapa kerusakan pada struktur bangunan sudah terjadi, seperti retak dan hancurnya selimut beton sehingga tulangan baja tidak terlindungi. Terdapat tulangan longitudinal pada kolom beton bertulang yang sudah mengalami deformasi berlebih dengan tulangan pengekang dengan jarak yang besar (Gambar 3)

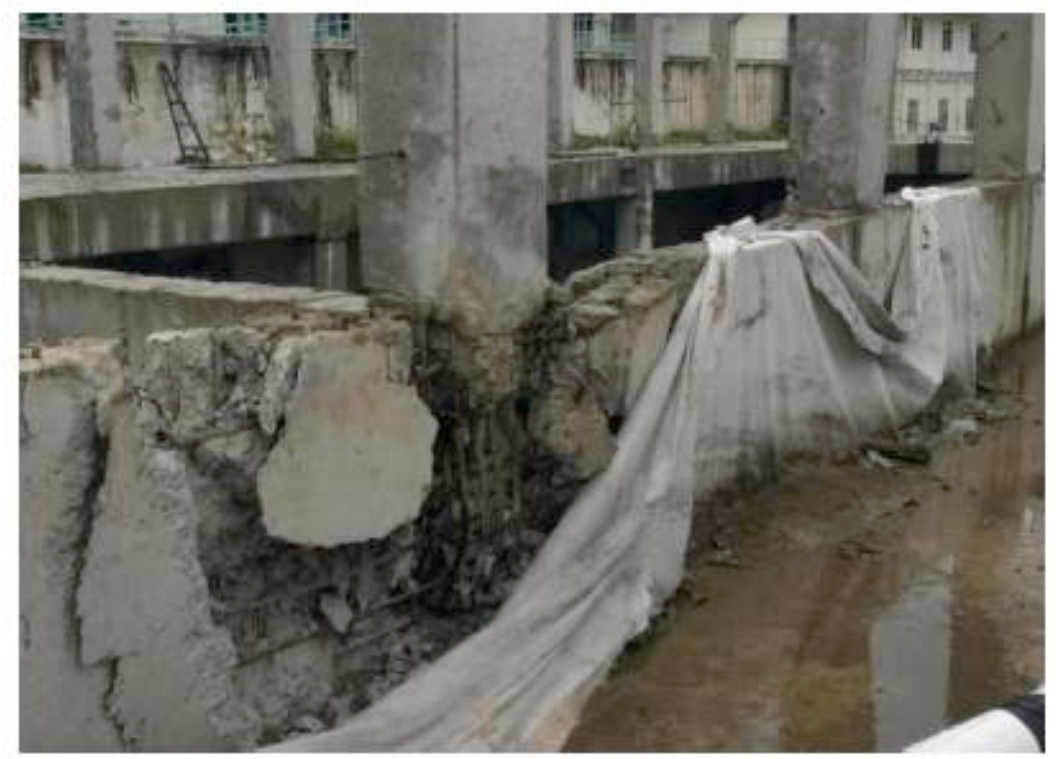

Gambar 3. Kerusakan Struktur Reservoir akibat Gaya Uplift

f. Ditemukan adanya kerusakan di daerah muka elemen bangunan, menunjukkan besarnya gaya yang bekerja pada daerah tersebut. (Gambar 4) 


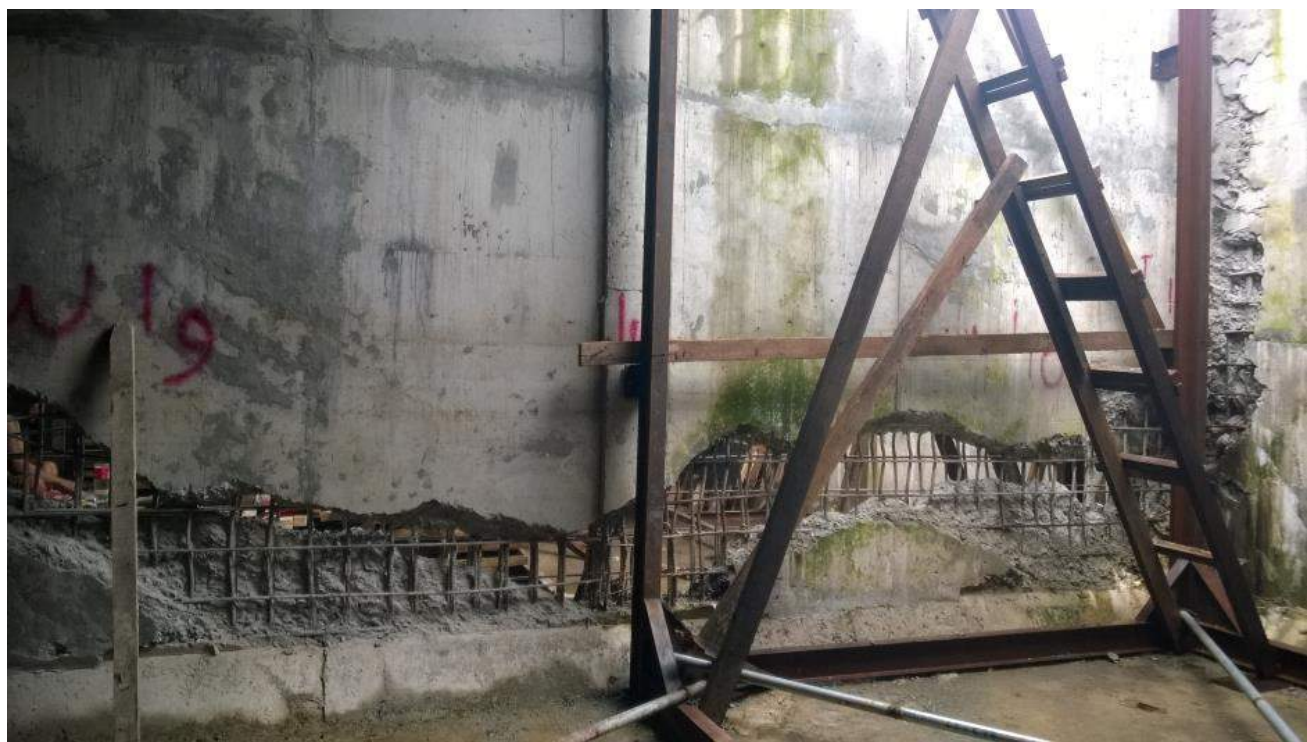

Gambar 4. Kerusakan pada Dinding Bangunan

g. Dibutuhkan counterweight untuk menyeimbangkan beban uplift yang bekerja. Counterweight berupa timbunan tanah dapat dilakukan, namun dibutuhkan sayap (wing) di bagian bawah muka bangunan sebagai area bertumpunya tanah timbunan.

h. Seperti ditunjukkan pada Gambar 5 bahwa bangunan sudah berada di atas permukaan tanah, hal ini mengindikasikan bahwa berat bangunan tidak dapat melawan gaya uplift yang begitu besar.

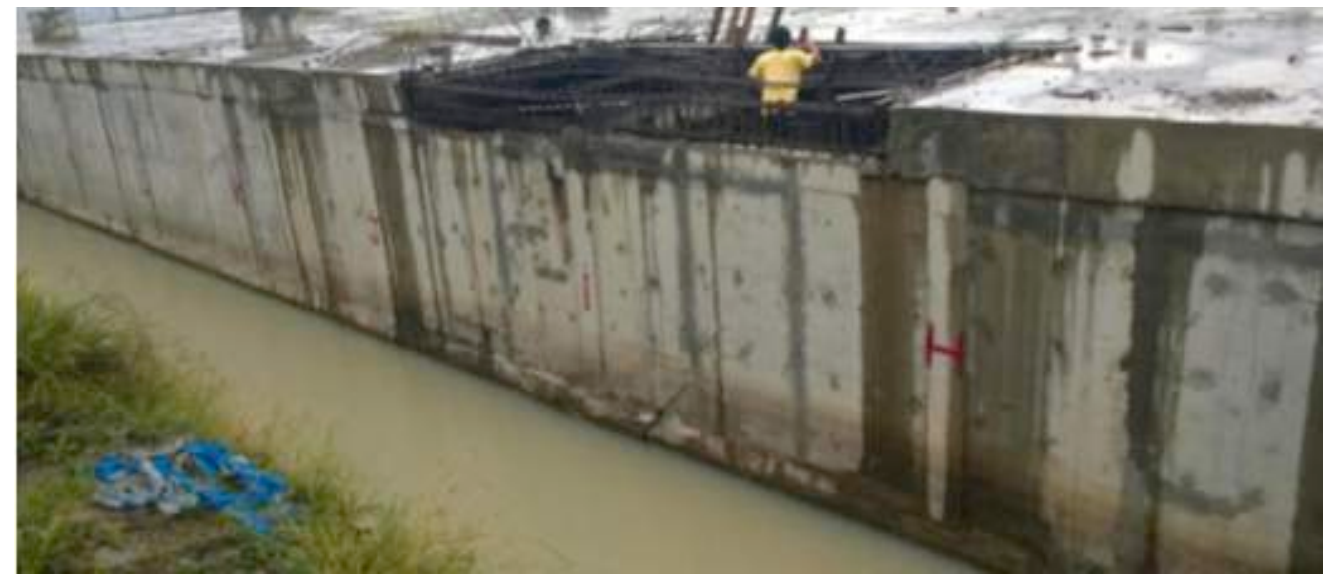

Gambar 5. Bangunan Reservoir yang Sudah Berada di atas Permukaan Tanah

i. Tidak terlihat adanya kebocoran pada pelat dasar dan pelat atas.

j. Secara teknis, bangunan reservoir ini masih dapat dipertahankan dan masih dapat digunakan dengan bentuk perbaikan-perbaikan.

Perbaikan elemen struktur yang dilakukan terhadap kondisi eksisting bangunan antara lain adalah:

(1) Perkuatan kolom seperti ditunjukkan pada Gambar 6 berikut: 

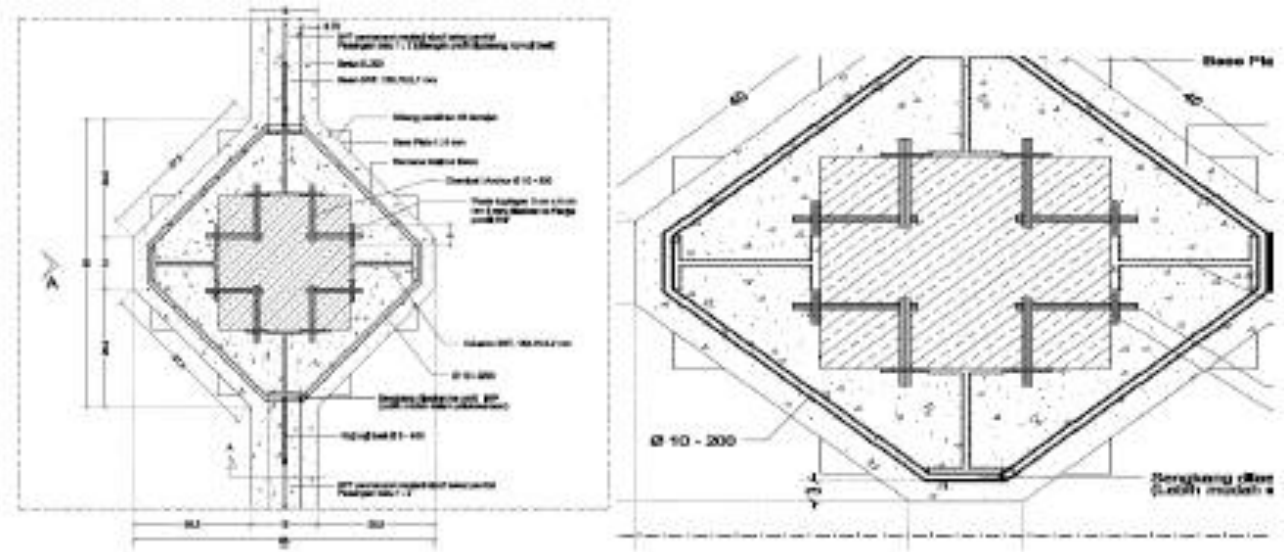

Gambar 6. Perkuatan Kolom

(2) Penebalan pelat bawah setinggi $32.5 \mathrm{~cm}$, sehingga tebal total adalah $57,5 \mathrm{~cm}$ dengan mutu beton K-350, dan penambahan 2 lapis tulangan (wire mesh) M12-150 dengan shear connector D13 - 500 (masing-masing dipasang sebagai tulangan atas dan bawah).

(3) Penebalan pelat atas setinggi $15 \mathrm{~cm}$, sehingga tebal total adalah $30 \mathrm{~cm}$ dengan mutu beton K-350, dan penambahan 2 lapis tulangan (wire mesh) M8-150 dengan shear connector D13 - 500 (dipasang sebagai tulangan atas saja)

(4) Penambahan beban tanah dikombinasikan dengan beton tumbuk untuk mengatasi beban uplift air tanah setinggi $4.61 \mathrm{~m}$.

Rencana Penambahan:

- Timbunan tanah, tebal $50 \mathrm{~cm}$

- Hamparan Beton Tumbuk, tebal 50cm.

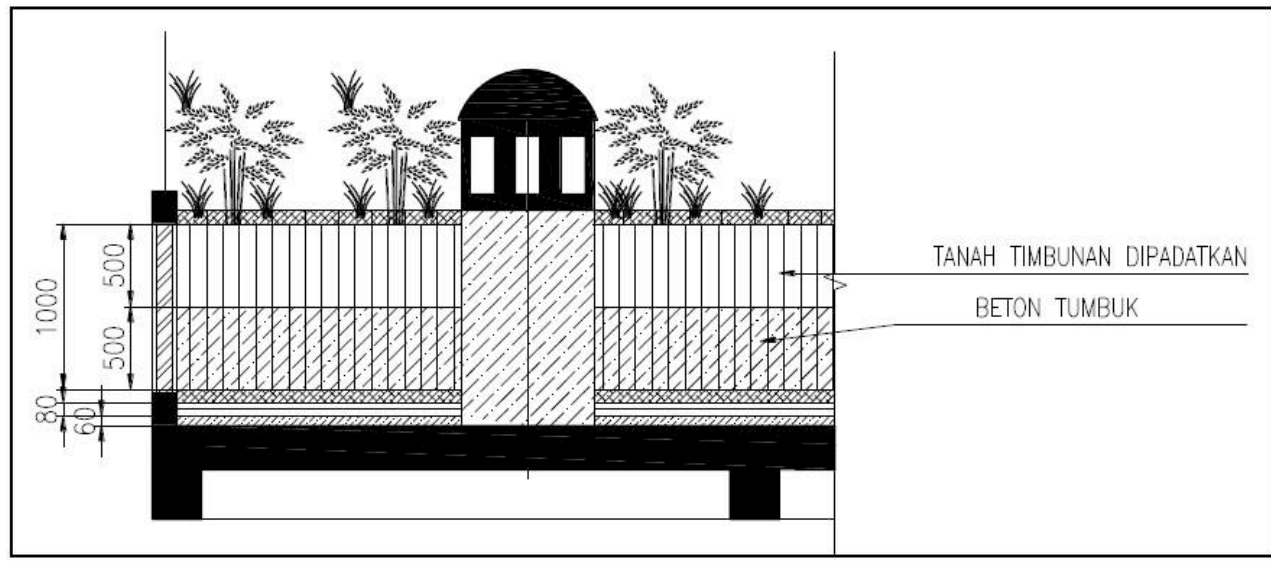

Gambar 7. Potongan Melintang Penambahan Timbunan Tanah di Atas Plat Reservoir 3

Berikut kondisi safety factor di area reservoir setelah perbaikan dengan uplift 3,954 m:

- Untuk kondisi kosong,

- Untuk kondisi maintenance tanpa tanah timbun,

- Untuk kondisi maintenance dengan tanah timbun,

- Untuk kondisi operasional tanpa tanah timbun,

- Untuk kondisi operasional dengan tanah timbun,
$\mathrm{SF}=0,785$

$\mathrm{SF}=1,305$

$\mathrm{SF}=1,877$

$\mathrm{SF}=1,826$

$\mathrm{SF}=2,398$ 
Berikut kondisi safety factor di area reservoir setelah perbaikan dengan uplift 4,610 m:

- Untuk kondisi kosong,

$\mathrm{SF}=0,617$

- Untuk kondisi maintenance tanpa tanah timbun,

$\mathrm{SF}=1,116$

- Untuk kondisi maintenance dengan tanah timbun,

$\mathrm{SF}=1,604$

- Untuk kondisi operasional tanpa tanah timbun,

$\mathrm{SF}=1,560$

- Untuk kondisi operasional dengan tanah timbun,

$\mathrm{SF}=2,049$

Berdasarkan hasil evaluasi nilai angka keamanan antara rekomendasi dengan aktual pelaksanaan diperoleh hasil pada area reservoir, angka keamanan pada setiap kondisi adalah meningkat dibandingkan dengan rekomendasi sebelumnya, dan sudah memenuhi syarat $\mathrm{SF}>1.25$.

Kasus ketiga adalah perencanaan reservoir baru dengan kapasitas $3000 \mathrm{~m}^{3}$.

Dilakukan penyelidikan tanah dan evaluasi geoteknik dilakukan untuk mendapatkan :

- Sistem pelapisan tanah di lapangan (soil stratification).

- Kekuatan pelapisan tanah pada setiap kedalaman yang ditinjau.

- Klasifikasi tanah berdasarkan pengujian lapangan (empiris) dan pengujian laboratorium.

- Evaluasi kedalaman muka air tanah (ground water level) di lapangan.

Untuk dapat melakukan evaluasi tersebut maka telah dilakukan penyelidikan di lapangan dengan menggunakan Uji Penetrasi Lapangan Dengan Sondir (SNI 2827-2008) dan Hand Boring. Pemodelan lapisan tanah dilakukan seperti gambar di bawah ini:

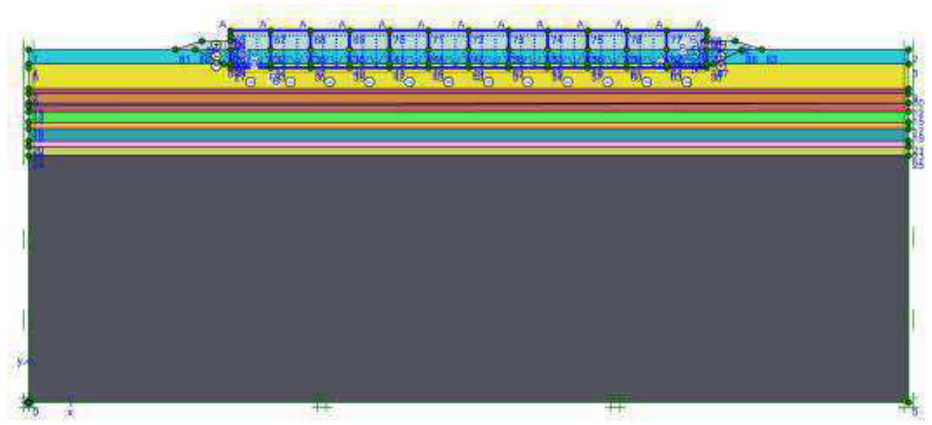

Gambar 8. Pemodelan Lapisan Tanah Dan Bangunan Reservoir Kasus Ketiga

Pada gambar di atas dilakukan pemodelan lapisan tanah, pemodelan galian tanah dengan slope 1:2, pemodelan struktur reservoir yang terdiri dari lantai, dinding, kolom struktur, dan juga penutup reservoir. Pemodelan ini dilakukan sesuai dengan kondisi di lapangan, mendekati kondisi sebenarnya bagaimana nanatinya pekerjaan ini akan dikerjakan.

Pada tahap operasional ini semua beban sudah bekerja dan reservoir bekerja, hasilnya adalah sebagai berikut: 
Dari hasil analisis maka penurunan differential adalah sebagai berikut: $4.40 \mathrm{~mm}$, relatif kecil sekali. Dari hasil analisis di atas dapat disimpulkan:

a. Reservoir aman terhadap gaya uplift.

b. Reservoir aman terhadap penurunan jangka pendek dan juga jangka panjang, baik terhadap penurunan total maupun terhadap penurunan differential.

c. Reservoir aman terhadap semua beban pada saat operasional

Selanjutnya dilakukan analisa struktur yang menghasilkan dimensi struktur reservoir. Bila sudah diperoleh dimensinya, maka kita dapat menghitung safety factor dari perencanaan yang kita lakukan. Berikutnya, harus dilakukan pula perhitungan safety factor berdasarkan perbandingan seluruh berat struktur terhadap berat air pada saat bangunan dalam keadaan kosong untuk mencegah terjadinya uplift: Begitu pula untuk perencanaan bangunan reservoir baru mengharuskan beban yang mampu menahan gaya uplift agar bangunan dapat beroperasi sesuai yang diharapkan. Bila berat struktur telah memadai untuk mencegah terjadinya uplift tersebut, kita dapat memperoleh dimensi struktur reservoir tersebut.

Perhitungan gaya uplift dihitung berdasarkan persamaan berikut:

$$
Q=\gamma \cdot z \cdot A
$$

Dengan:

$\begin{array}{lll}Q & = & \text { Gaya uplift }(\mathrm{kN}) \\ \gamma & = & \text { berat jenis air }\left(\mathrm{kN} / \mathrm{m}^{3}\right) \\ z & = & \text { beda tinggi elevasi muka air terhadap dasar reservoir } \\ A & = & \text { Luas dasar reservoir }\end{array}$

Berikut perhitungan berat bangunan dalam keadaan kosong, bila diketahui:

$\begin{array}{llll}\gamma \text { air } \quad= & 10 \mathrm{kN} / \mathrm{m}^{3} \\ \gamma \text { tanah } & 17,5 \mathrm{kN} / \mathrm{m}^{3} \\ \text { Elevasi dasar reservoir } & = & +1,023 \mathrm{~m} \\ \text { Elevasi muka air tanah } & = & +2,5 \mathrm{~m} \\ \text { Beda tinggi, } \mathrm{z} & = & 1,477 \mathrm{~m} \\ & \text { A } & = & 1080 \mathrm{~m}^{2}\end{array}$

Berat reservoir total (W) $=24121,518 \mathrm{kN}$

Maka gaya uplift adalah, $Q=15951,6 \mathrm{kN}$

Safety factor dihitung dengan persamaan:

Maka diperoleh $\mathrm{SF}=1,512>1,25$.

$$
S F=\frac{W}{Q}
$$

Di mana kondisi struktur akan aman terhadap bahaya uplift.

\section{Kesimpulan dan Saran}

Dari ketiga kasus baik dalam perbaikan dan perencanaan struktur reservoir dapat diambil kesimpulan sebagai berikut:

- Untuk kasus pertama, kondisi SF struktur sebelum perbaikan adalah 0,1798 dan mengalami kenaikan sampai 1,2 m. Untuk mengatasi hal ini yakni dengan menambah tanah timbun dan penebalan pelat lantai dari sebelumnya $25 \mathrm{~cm}$. Jika terjadi heaving sebesar 6,477 cm dilakukan pemasangan ground anchored dengan jumlah dua per potongan dengan jarak pemasangan $8 \mathrm{~m}$. 
- Pada kasus kedua, akibat kerusakan dilakukan perbaikan kolom, penebalan pelat lantai bawah setinggi $32,5 \mathrm{~cm}$, penambahan pelat lantai sebesar $15 \mathrm{~cm}$, dan penambahan tanah timbun sehingga SF di atas 1,25 tercapai.

- Sedangkan pada kasus 3 yang merupakan perencanaan reservoir baru, dilakukan analisa terhadap kondisi operasional yang relatif kecil yakni 4,40 mm dan $\mathrm{SF}=1.512$

\section{Daftar Pustaka}

Anchor, R. D. (1992). Design of Liquid Retaining Concrete Structures. London

U.S. Department of Transportation Federal Highway Administration. (1999). Ground Anchors and Anchored Systems. Washington, D.C

American Concrete Institute. (2004). Design Considerations for Enviromental Engineering Concrete Structures (ACI 350.4R-04). Farmington Hills

British Standard Institute. (1989). British Standard Code of Practice for Ground Anchorages (BS 8081:1989). London

Badan Standarisasi Nasional. (2008). Cara Uji Penetrasi Lapangan Dengan Sondir (SNI 2827-2008). Jakarta 